\title{
The role of pre-reflexive processes in learning how to fight: contributions from phenomenology
}

\author{
Thabata CASTELO BRANCO TELLES* \& Cristiano BARREIRA \\ University of São Paulo (Brazil)
}

8th IMACSSS International Conference Abstracts, Viseu (Portugal), October 10-12, 2019

Type: Oral communication

\begin{abstract}
This study consists of a description on pre-reflexive processes in learning how to fight. The objective of this investigation is to present and discuss them through phenomenology as a philosophical and methodological point of view. It is a way to comprehend each phenomenon from its own structure, not apart from the reality of those who live it. In embodied corporal practices, the body constantly moves and there is not much time for the practitioner to reflect before choosing and doing each technique. We briefly present the main concepts to promote an understanding on pre-reflexive acts through phenomenology: body, awareness/consciousness, perception, body schema, habit. This can broaden the way we usually see the learning processes, which cannot count only on explanation of techniques. A practice to be embodied must be lived by the body. We must enable the bodies to be challenged not only to learn or master a technique but also to generate new perceptions and movements in the situations we are in. One can only learn how to fight when fighting.
\end{abstract}

Keywords: Phenomenology; martial arts; combat sports; sports psychology; embodiment.

\section{Introduction, Objectives and Methodology}

As a philosophical and methodological point of view, phenomenology aims at comprehending each phenomenon from its own structure as well as trying to find solutions which are not apart from the reality of those who live it. As discussed by Merleau-Ponty (1945/2000), phenomenology is only accessible through a phenomenological method, and it is not a theory or simply a method that we can choose to use, but it is rather a particular lens through which we can view the world and phenomena around us. In order to do this, our approach is guided by the concept of "bracketing", an attitudinal stepping back from our taken for granted assumptions of the world. We consider phenomenology as a point of view and not simply a theory or a method alone and the description is of such fundamental importance to a phenomenological research.

Through a phenomenological approach in fighting practices we highlight the importance of comprehending them in both reflexive and non-reflexive ways, as while fighting the body constantly moves and there is not much time for the practitioner to reflect before choosing and doing each technique. When considering verbal communication, it involves trying to put these acts into language (Stelter, 2000) and this comprehension consists of a reflection about the unreflecting (Barbaras, 2008). As discussed by Merleau-Ponty (1945/2000; 1953/2011), a movement is not only related to what we think about the world, but also to what we can do in it (and through it). This phenomenological understanding pertains that a movement is never randomly executed, but on the contrary, it is always related to an object and to the world, even if we are not conscious of it (Merleay-Ponty, 1945/2000.) We do it, always engaged in a specific situation. Thus, the objective of this investigation is to present and discuss pre-reflexive processes in learning how to fight, through phenomenology as a philosophical and methodological perspective.

\section{Results and discussion}

In a phenomenological point of view on pre-reflexive practices, one needs to differ consciousness (more attached to reflexive processes) from awareness (usually tied to pre-reflexive

*Email: thabata@gmail.com

(C) 2019 Universidad de León. www.unileon.es 
ones). These are related to a sensible perception which "is not necessarily conscious. [...] The body is in action before being conscious of it" (Andrieu, 2017, p. 23). Then, the consciousness of the action can only happen after the action itself and it requires a reflexive process, while awareness not necessarily requires a conscious reflection.

The key to understand these relations relies in the notion of perception, one of the most relevant topics in Merleau-Ponty's phenomenology. He stated that it is our first way to access the world. When it comes to bodily practices, it is from the perception that the body starts to move. It is also relevant to mention that we usually move enacted by contours, as we can never look at something entirely. Although we are not able to see the entire object, we can recognize it as a relief, which enables our actions (Merleau-Ponty, 1953/2011).

According to this perspective, we can usually perceive something once we can put together apparently separated information from what we see, hear or touch, for example. We do not consider the relationship between subject and object as something related just to what we "think", but also to what we "can". This involves not only perceiving the object, but also an specific situation and how to be able to do something in a certain time and space. This is how we can develop body confidence: from a learning process to the creation of a habit.

Another important aspect on perception in MA\&CS is the role of the opponent. This is what enables each one of us to deal with unexpected situations. When fighting, even mastering a lot of techniques, we constantly face what we cannot control or predict because we are always dealing with someone else. The opponent is someone who fights with us but is different from ourselves and pushes us to constantly deal with unpredict situations. Fighting consists in a dynamic process of letting the body act from previous learned movements while being presented to an unexpected situation from the opponent.

Still related to the perception and the role of the opponent, we consider the body schema as a relevant aspect in the perceptual act. To Gallagher (2005) "it involves certain motor capacities, abilities, and habits that both enable and constrain movement and the maintenance of posture. It continues to operate, and in many cases operates best, when the intentional object of perception is something other than one's own body" (p. 24). This citation underlines the importance of the opponent to develop motor capacities and abilities. This otherness helps the body to generate something new from what it already knows how to do, challenging the body schema. This notion is understood as a marginal awareness of the body, as we do not usually access it, although it is always there. A fighter does not need to think about how to bend the knee before kicking as the body already knows how to do it. From this assumption we derive the notion of habit (Saint-Aubert, 2013), which can be comprehended not as an automatism or a knowledge, but tied to a bodily intelligence. The habit enables further actions, either in a motor or perceptive way.

\section{Conclusion}

Although briefly, we presented here the main concepts to promote an understanding on pre-reflexive acts through phenomenology: body, awareness/consciousness, perception, body schema, habit. This can broaden the way we usually see the learning processes, which cannot count only with explanation of techniques. As we have seen, a practice to be embodied must be lived by the body. We must enable the bodies to be challenged not only to learn or master a technique but also to generate new perceptions and movements in the situations we are in. One can only learn how to fight when fighting.

\section{References}

Andrieu, B. (2017). Apprendre de son corps: une méthode émersive au CNAC. Mont-Saint-Aignan Cedex: Presses Universitaires de Rouen et du Havre.

Barbaras, R. (2008). Motricité et phénoménalité chez le dernier Merleau-Ponty. In E. Saint-Aubert, E. (org.), Maurice Merleau-Ponty (pp. 27-42). Paris: Hermann Éditeurs.

Barreira, C.R.A. (2017). The essences of martial arts and corporal fighting: a classical phenomenological analysis. Archives of Budo, 13, 351-376.

Gallagher, S. (2005). How the body shapes the mind. Oxford: Oxford University Press. 
Merleau-Ponty, M. (2000). A fenomenologia da percepção. São Paulo: Martins Fontes. (Obra originalmente publicada em 1945).

Merleau-Ponty, M. (2011). Le monde sensible et le monde d'expression (Cours au Collège de France notes, 1953). Genebra: Métis Presses.

Stelter, R. (2000). The transformation of body experience into language. Journal of Phenomenological Psychology, 31(1), 63-77. doi: $10.1163 / 156916200746256$

Telles, T. C. B. (2018). Corpo a corpo: um estudo fenomenológico no karate, na capoeira e no MMA (PhD thesis). University of São Paulo.

Telles, T.C.B., Vaittinen, A., \& Barreira, C.R.A. (2018). Karate, capoeira and MMA: a phenomenological approach to the process of starting a fight. Revista de Artes Marciales Asiáticas, 13(2), 114-130. doi: 10.18002/rama.v13i2.5119 